\title{
ON AN URTICARIAL RESPONSE TO LIGHT AND ITS PHOTOPHYSIOLOGY ${ }^{1}$
}

\author{
By HAROLD F. BLUM, H. ALLINGTON aNd R. WEST \\ (From the Division of Physiology, University of California Medical School and \\ the Cowell Memorial Hospital, Berkeley)
}

(Received for publication January 28, 1935)

The opportunity has recently been afforded to study a case of abnormal sensitivity to sunlight which fits the description of urticaria solaris given by Duke (1923) and others. Certain observations have been made which shed considerable light upon the photophysiology and photopathology of skin and will be described herein. The clinical findings will be reviewed elsewhere in the near future and it will suffice here to say that the patient has appeared at the time of our observations, and subsequently, to be completely normal, except in the fact that a few minutes' exposure to sunlight produces an immediate and severe erythema and edema accompanied by itching. The type of reaction involved appears to be sharply differentiated from the normal reactions of the skin to light, and in the following discussion we will follow the plan of contrasting the two phenomena.

General description. When a portion of the skin of this individual is exposed to sunlight for a few minutes, a marked erythema and edema appear. With short exposures, say two minutes, the erythema may not appear until a few minutes after the cessation of the irradiation. This erythema is discreetly limited to the area exposed. After a short time edema appears, likewise restricted to the exposed area, and still later an erythema develops surrounding and spreading outward from the edematous area. Figure 1 shows the appearance of the edema and erythema following an irradiation of three minutes. A very short exposure may result in an erythema only, without edema. In all cases, even the most severe, both edema and erythema disappear in the course of a few hours, leaving no discoloration of the exposed skin nor any other trace of the occurrence.

The resemblance to the "triple response" described by Lewis (1927) is striking. He clearly

1 This investigation was assisted by a grant from the Board of Research of the University of California. demonstrated the similarity of such reactions to that produced by histamine pricks and formulated the hypothesis that a histamine-like " $\mathrm{H}$ " substance is released as the result of cell damage and is responsible for the "triple response." We are immediately led to the hypothesis that in the case herein described, a photochemical reaction occurs in the skin which results in the release of " $\mathrm{H}$ " substance.

This type of response differs very markedly from the reaction of normal skin to ultraviolet light. For example, immediately following exposure of a normal skin to the radiation from a quartz mercury arc, no erythema is observable other than a slight one produced by heat. After a period of an hour or more, an erythema appears which may persist for a day or more, and pigmentation begins to appear before this erythema has subsided; edema does not ordinarily occur as a result of moderate doses. While Lewis (1927) believed that the delayed erythemic response following ultraviolet irradiation is an example of the "triple response," resulting from the elaboration of " $\mathrm{H}$ ” substance, Krogh (1929) contended that it is probably dependent upon the production of another less diffusible substance. At any rate, the difference in the rate of appearance of the abnormal response and that of the normal, a matter of minutes as against hours, indicates a distinct difference in the two processes even if both be the result of production of " $\mathrm{H}$ " substance.

The active wave lengths. In Figure $2 \mathrm{~A}$ is shown a curve representing the relative effectiveness of the wave lengths which elicit the erythema of normal skin. ${ }^{2}$ It will be seen that the erythema-producing radiations are limited to those of wave lengths less than $3200 \AA$, and that there is a sharp band of active wave lengths having its maximum at $2970 \AA$. Proceeding toward the

2 The curve is taken from that of Lukiesh, Holladay and Taylor (1930). 


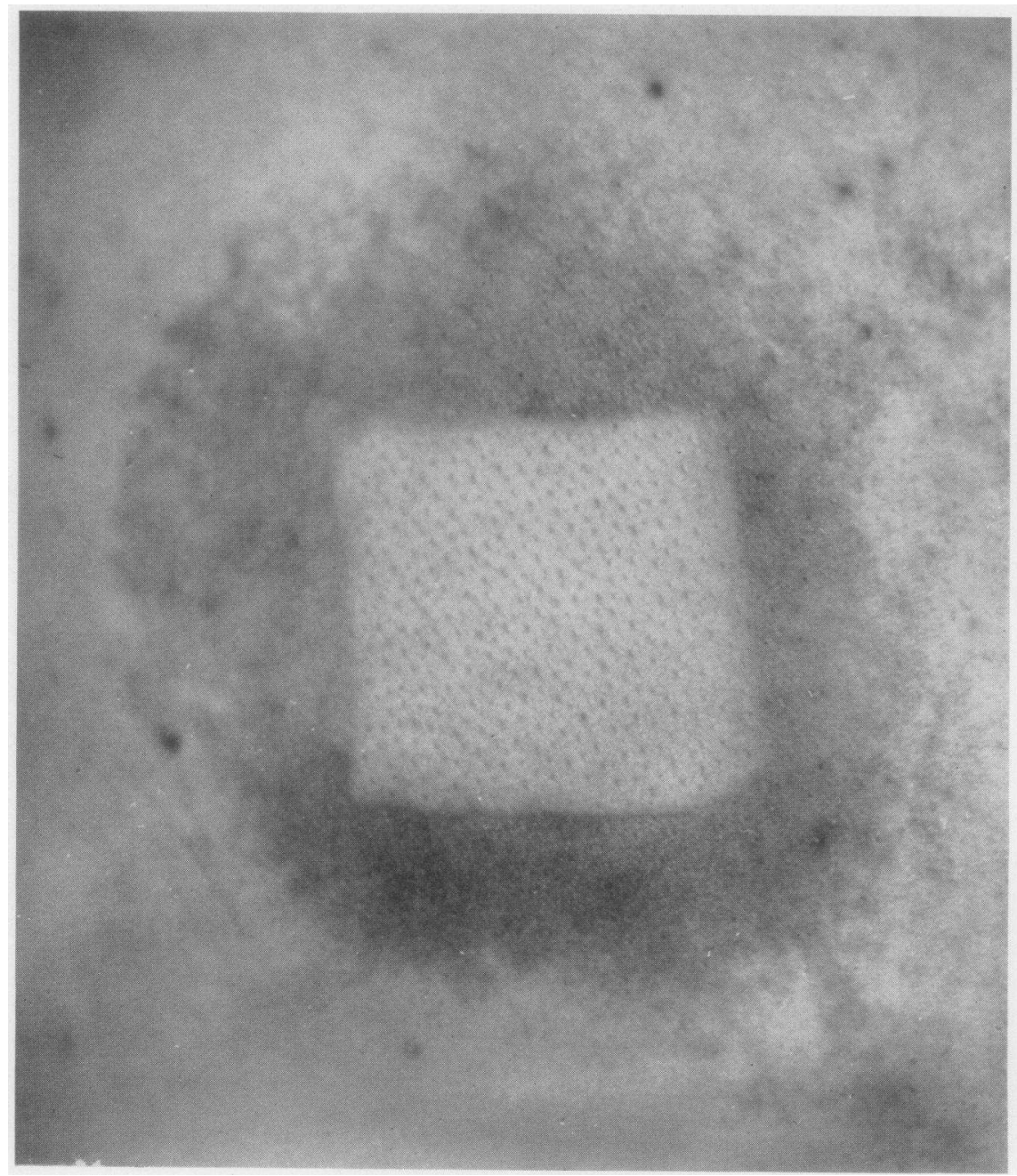

FIG. 1. Urticarial reaction of skin of back following 3 minutes of exposure to sunlight. The square area of edema corresponds to the area exposed to the sun's rays. The spreading area of erythema around the edematous region is clearly shown.

short wave lengths of the spectrum, a minimum occurs at about $2800 \AA$ followed by a second increase in effectiveness. Three groups of workers agree on the position of the maximum at $2970 \AA$, but there is not complete agreement as to the values for the shorter wave lengths. In general there seems to be some disagreement as to whether pigment production corresponds to exactly the same wave lengths as erythema production, but certainly the agreement is good in the region of $2970 \AA .^{3}$

From the curve it is reasonable to assume that the maximum at $2970 \AA$ represents an absorption

\footnotetext{
${ }^{3}$ For a discussion of this see Laurens (1933).
}

band of some compound which when activated brings about reactions which end in the production of erythema and pigmentation. Obviously, an abnormal sensitivity to sunlight might represent an enhanced activity of this normal erythema-producing mechanism, but in this case the wave lengths active in bringing it about must be the same as those which elicit the normal reaction.

For this reason it is important to know the wave lengths which are active in bringing about abnormal skin effects, and we have made a sufficient number of observations to determine effectively the wave lengths which bring about the abnormal edema and erythema in our patient. Table I shows the results of various exposures to 


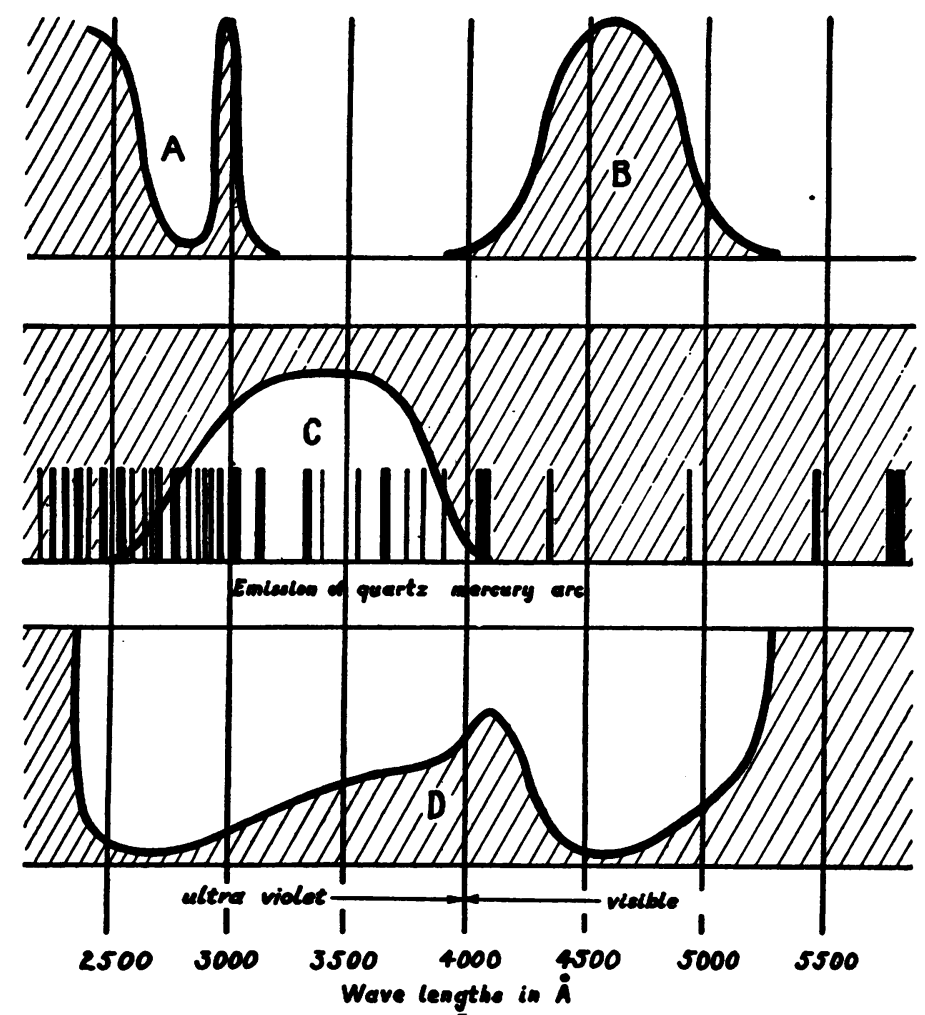

Fig. 2. $A$, spectral region producing normal delayed erythema response (after Luckiesh, Holladay and Taylor (1930)). B, spectral region producing abnormal "triple response" in our patient (roughly approximate). $C$, transmission of Corning 986 filter. The approximate spectral position and relative intensity of the lines emitted by the quartz mercury arc are also shown. $D$, absorption spectrum of "hematoporphyrin." (Composite from several porphyrins, after Hausmann and Krumpel (1927).)

the sun's rays. An examination of these data will demonstrate that the active wave lengths lie between 3900 and $5300 \AA$ and that only the region between 4100 and $4900 \AA$ is very active, since only erythema or very slight edema was produced after long exposure to the region between 3900 and $4100 \AA$, and to that between 4900 and $5300 \AA$. Thus for rough purposes we may say that the active region lies between 4000 and $5000 \AA$. Observations using the quartz mercury arc, which are also described in Table I, correspond with those for sunlight. Fifteen minutes of irradiation at $25 \mathrm{~cm}$. distance, with the $4050 \AA$ line virtually removed and all longer wave lengths in the visible region completely eliminated by the use of Corning 986, failed to produce any trace of the immediate " triple response," although it produced a strong delayed erythema followed by pigmentation. On the other hand, the full radiation from the arc, or only those lines passing through window glass, i.e., above $3200 \AA$, produced a slight erythema in the same time. Reference to Figure 2C shows the lines of the mercury arc; the general lack of radiation in the spectral region producing the immediate "triple response," i.e., between 4000 and $5000 \AA$, is evident. By controlling various factors it might be possible to obtain a more exact estimation of the effectiveness of various wave lengths, but as it seemed that little was to be learned from more exact data this study was not carried further.

So far as they go, these observations demonstrate a number of very striking facts. In Figure $2 \mathrm{~B}$ the active wave length for this response is represented approximately and may be compared with that for the erythema response of normal 
TABLE I

Delimitation of active spectral region

\begin{tabular}{|c|c|c|c|c|}
\hline Source & $\begin{array}{c}\text { Filter } \\
\text { Corning } \\
\text { number }\end{array}$ & $\begin{array}{l}\text { Wave lengths } \\
\text { passed by } \\
\text { filter }\end{array}$ & $\begin{array}{l}\text { Duration } \\
\text { of } \\
\text { exposure }\end{array}$ & Result \\
\hline 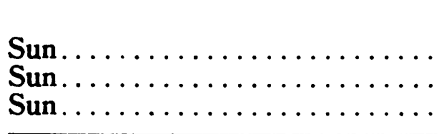 & $\begin{array}{l}246 \\
351 \\
586\end{array}$ & $\begin{array}{c}\text { Longer than } 5800 \\
\text { Longer than } 5300 \\
3300-3900\end{array}$ & $\begin{array}{c}\text { minutes } \\
31 \\
30 \\
30\end{array}$ & $\begin{array}{l}\text { No reaction } \\
\text { No reaction } \\
\text { No reaction }\end{array}$ \\
\hline 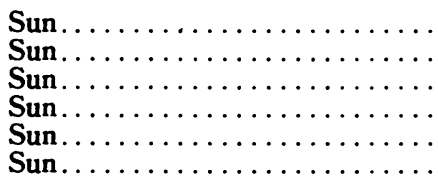 & $\begin{array}{c}338 \mathrm{a} \\
338 \mathrm{a} \\
338 \mathrm{~b} \\
986 \\
986 \\
\text { Window glass }\end{array}$ & $\begin{array}{c}\text { Longer than } 4900 \\
\text { Longer than } 4900 \\
\text { Longer than } 4800 \\
2500-4100 \\
2500-4100 \\
\text { Longer than } 3200\end{array}$ & $\begin{array}{c}12 \\
31 \\
7 \\
12 \\
31 \\
1.5\end{array}$ & $\begin{array}{l}\text { Erythema (slight) } \\
\text { Erythema (very slight) } \\
\text { Erythema (slight) } \\
\text { Erythema } \\
\text { Erythema } \\
\text { Erythema }\end{array}$ \\
\hline 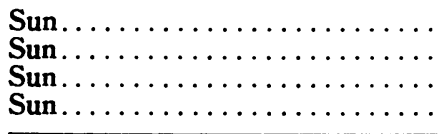 & $\begin{array}{c}970 \\
\text { None } \\
\text { Window glass } \\
352\end{array}$ & $\begin{array}{l}\text { Longer than } 2500 \\
\text { All } \\
\text { Longer than } 3200 \\
\text { Longer than } 5000\end{array}$ & $\begin{array}{r}9 \\
9 \\
7 \\
30\end{array}$ & $\begin{array}{l}\text { Edema } \\
\text { Edema } \\
\text { Edema } \\
\text { Edema (very slight) }\end{array}$ \\
\hline $\begin{array}{l}\text { Quartz mercury arc } 15 \mathrm{~cm} . \ldots \ldots \\
\text { Quartz mercury arc } 15 \mathrm{~cm} . \ldots \ldots \\
\text { Quartz mercury arc } 15 \mathrm{~cm} . \ldots \ldots\end{array}$ & $\begin{array}{c}\text { None } \\
\text { Window glass } \\
986\end{array}$ & $\begin{array}{l}\text { All lines } \\
\text { Longer than } 3200 \\
2500-4100\end{array}$ & $\begin{array}{l}15 \\
15 \\
15\end{array}$ & $\begin{array}{l}\text { Erythema (slight) } \\
\text { Erythema (slight) } \\
\text { No reaction }\end{array}$ \\
\hline
\end{tabular}

skin (Figure 2A); it may be readily seen that there is no correspondence whatsoever between the regions of wave lengths effective in producing the two types of response. Lacking any other proof, this tells us that the primary photochemical reactions responsible for the two effects are distinctly different, i.e., involve totally different photoactive substances.

This is still more strikingly shown by the demonstration of a normal erythema and pigment response in the same individual who shows the abnormal immediate "triple response." When exposed to those radiations from the quartz mercury arc which pass through Corning 986 no immediate erythema or edema was produced. Erythema appeared, however, in the course of an hour or more not accompanied by edema, and followed by pigmentation, the reaction being in all ways comparable to that of a normal skin. The transmission of Corning 986 is shown in Figure 2C together with the positions of the lines emitted by the mercury arc, and as will be seen by reference to this figure, Corning 986 virtually removes all the lines which produce the abnormal "triple response," while transmitting most of those lines which are active in eliciting the normal erythema and pigmentation.

It will be seen from the above that this individual has to all appearances normal erythema and pigment mechanisms but has in addition, independent of the first, a photochemical system which produces the abnormal immediate "triple response." This is of considerable interest from the clinical point of view, for we have here to consider a condition which apparently arises from the activity of a photochemically reactive molecule which normally is either not present or for some reason fails to produce the immediate "triple response." Thus to choose any treatment designed to correct an excess of the normal photophysiological mechanisms would be illogical.

Duke (1923, 1925), Frei (1925), and ValleryRadot and co-workers $(1926,1928)$ attempted to treat their patients, who were apparently suffering from the same condition as ours (see below), by repeated exposure in the attempt to exhaust the pathological mechanism. Their results were not highly successful, although some degree of tolerance may have been achieved. Our patient has developed a certain degree of tolerance to sunlight on his hands and face, i.e., he can tolerate an amount of light on these parts which would produce a severe edema on parts of the body ordinarily protected by clothing. It seems reasonable to assume that at least the major part of the tolerance developed on the hands and face is due to pigmentation developed by the small quantities of 'ultraviolet radiation which these parts received by occasional short exposure to the sun. 
By successive irradiations of an area of the upper arm with the quartz mercury arc through Corning 986 we were able to develop a strong pigmentation, which provided a certain degree of protection from the sun's rays. When this area of the skin was exposed to the sun's rays simultaneously with the corresponding area of the other non-pigmented arm, the edema which developed on the pigmented arm was much less pronounced, apparently because of the absorption of the rays between 3900 and $5300 \AA$ by the pigment. We are at present attempting to pigment the face in the same manner in order to obtain protection against the light rays.

In order to test definitely the possibility of increased tolerance by continued irradiation with the same wave lengths which produce the abnormal response, we repeatedly exposed an area of the forearm to the sun's rays filtered through window glass to remove all the wave lengths below $3200 \AA$. The exposures lasted several minutes ( 5 to 15 ) and were made once or twice every day for one week. A marked edema was produced at each exposure, which was approximately as great at the end of the week as before; some decrease in the reaction may have occurred but certainly it was not very marked. No persisting changes in the skin could be observed. There was no trace of pigmentation of the skin, thus demonstrating conclusively that this abnormal erythemic response has no relationship to the mechanism producing pigmentation.

The photoactive pigment. From the evidence we are led to the conclusion that at some point in the skin of this individual a photochemically reactive compound is present which when activated sets off a reaction that eventually results in tissue injury and the "triple response." This compound must have an absorption band corresponding to the wave lengths active in producing this reaction, i.e., must lie between 3900 and $5300 \AA$. We are left to search for such a pigment.

Hematoporphyrin or similar porphyrins have been suspected for a long time as the etiological agents in hydroa aestivale sue vacciniforme as well as in other clinically distinct types of photosensitization. This etiology has never been definitely established, as pointed out by Blum (1933), for it has never been demonstrated that the der- matological symptoms of hydroa can be produced by wave lengths which are absorbed by these porphyrins. In the present case hematoporphyrin, uroporphyrin and koproporphyrin are all definitely ruled out as the photoactive compound, because these substances do not show an absorption band between 3900 and $5300 \AA$. Hausmann and Krumpel (1927) have studied the absorption of these porphyrins, and none shows absorption in this region. In Figure $2 \mathrm{D}$ we have drawn a curve to represent the absorption spectrum of these porphyrin compounds; the curve may be considered as a composite of Hausmann's and Krumpel's spectral absorption curves, which are nearly identical for all the porphyrins that they studied. On comparing this curve with the wave length region which produced the immediate "triple response" in our patient, it will be observed that there is a complete lack of agreement, for the porphyrin curve shows a minimum of absorption just at the position of the active radiations. It seems probable that the importance of hematoporphyrin has been greatly overemphasized in relation to photosensitization, and the investigations of Templeton and Lunsford (1932) suggest that hematoporphyrinuria is a result rather than a causal factor, since it often appears in normal individuals after exposure to ultraviolet light.

One of the facts which has contributed to the widespread acceptance of hematoporphyrin as a causal factor in photosensitization is that this compound is capable of producing destructive effects in biological systems in general. Such photosensitization, produced by many dyes, is commonly referred to as photodynamic action (see Blum, 1932). Recently Blum and Spealman (1934) have summarized the facts, indicating that sensitization by all those dyes studied, including hematoporphyrin, takes place only in the presence of molecular oxygen. We have been interested in testing whether the photochemical reaction involved in the production of this abnormal "triple response" is dependent, similarly, upon the presence of $\mathrm{O}_{2}$. To do so, the circulation was cut off from one arm by means of a sphygmomanometer cuff, this condition being maintained for ten minutes in the hope of producing a high degree of anoxemia. A small area of the skin was then exposed to sunlight for periods of from one and one-half to three minutes, 
the circulation remaining cut off during this period. A corresponding portion of the opposite arm was exposed simultaneously for comparison. After the reactive hyperemia following removal of the cuff had subsided, the two arms were compared; both showed erythema and edema in comparable degree. This was true in a number of experiments. While these results would suggest that $\mathrm{O}_{2}$ is not necessary for the reaction, they cannot be considered as absolutely eliminating this possibility, since it is impossible to say definitely whether or not a high degree of anoxemia was produced in the skin of the arm, and Blum and Spealman (1934) found that a very low $\mathrm{O}_{2}$ tension must be established in order to abolish such reactions. Thus the results cannot be accepted as conclusive, although if they were they would indicate that the reaction herein described does not belong to the type of photosensitization produced by hematoporphyrin in the laboratory.

On considering these facts we were not surprised to find that porphyrin could not be demonstrated in the urine of our patient. Duke (1925), Frei (1925) and Vallery-Radot et al. (1926) were likewise unable to demonstrate porphyrin in the urine of their patients.

We must look further for a pigment which will satisfy the requirements, but we have no great hope of success. Bile pigments are reported to be photoactive but their absorption spectrum does not meet the requirements, and moreover our patient showed no indication of jaundice and no excess of bile pigments in the urine. We know of no hem compound which has the required absorption spectra. The "yellow ferment" of Warburg and Christian (1933) has its absorption in the same spectral region which is effective in the production of the immediate "triple response," but any explanation in terms of this compound must be highly speculative. For the present we must be content with evidence proving the existence of a photosensitizing substance without being able to identify it.

Relationship to other conditions. As Lewis (1927) has pointed out, many irritating substances may produce the "triple response." Thus the urticarias, while probably all resulting from tissue injury and resultant “ $\mathrm{H}$ " substance production, may be brought about by quite dissimilar mechanisms. It seems probable that the present example of photosensitivity has little relationship with the allergies, though the tendency has been to place such cases in this class (see Duke, 1925). The fundamental mechanism would appear to be different, namely, the production of " $\mathrm{H}$ " substance following the photoactivation of a particular kind of light-absorbing molecule. The classification of this type of reaction with the " physical allergies," e.g., reactions to 'heat and cold, by Duke (1925) is perhaps somewhat misleading; actually the problem is a photochemical one and is simplified when considered as such.

The relationship to other types of photosensitivity, e.g., hydroa, eczema solare, lupus erythematosus, etc., is extremely interesting. While it is possible that all such conditions have a common etiological factor, this is by no means a necessary assumption and seems highly improbable. The symptoms are different enough to be given distinctly separate clinical classifications, although the custom seems to differ. Rasch (1926) suggests a relationship between certain of the separately classified conditions, but the identity of a common photochemically active sensitizer has never been definitely established, and in only one condition-that herein described-has the spectral region of absorption of such a sensitizer, i.e., the effective wave lengths, been clearly delimited.

Duke (1923) has described a case in all ways comparable with ours, in which the response was likewise elicited by violet and blue light. The case described by Frei (1925) and the two by Vallery-Radot et al. $(1926,1928)$ were also definitely sensitive to violet and blue light, and the latter investigators delimited the spectral region between 4000 and $5500 \AA$ (1926), which agrees with ours within the accuracy of the methods. One of Wucherpfennig's (1928) cases (designated HW.) probably belongs to this group. Although the active wave lengths given by this author do not agree exactly with ours, there seem to be objections to his method of measurement which may account for the apparent difference. The cases described by Ward (1905) and by Cummings (1926) were also sensitive to wave lengths greater than $3200 \AA,{ }^{4}$ but the spectral region was not delimited further than by the ob-

\footnotetext{
4 Through window glass.
} 
servation that the patients were sensitive through window glass. Their cases probably represent, however, the same condition as that described herein.

The case which Beinhauer (1925) studied and described as urticaria solaris manifested an immediate "triple response" and was in this respect similar to the cases mentioned above. However, in that case the response was elicited by an altogether different part of the spectrum, i.e., by wave lengths shorter than $3200 \AA .^{5}$ Therefore, it must have been etiologically different. Two of Wucherpfennig's (1928) cases (designated $\mathrm{Pa}$. and Mi.) may or may not belong to the same category as Beinhauer's but are certainly not the same as ours, Duke's or Vallery-Radot's.

The case of Weiss (1932) was apparently distinct from ours in that the urticarial reaction was delayed about four and one-half hours, and that it was produced by quartz mercury arc radiation, which was barely effective in our case.

In the very interesting series of Barber, Howitt and Knott (1926) all the patients appear to have shown some degree of eczema, which was absent in our case and in those to which reference has just been made. It would seem proper, therefore, to classify their cases as eczema solare. Unfortunately, the investigations by these authors of the spectral region of the radiation evoking the response in the skin were not exact enough for us to compare this feature of their cases with ours. It would appear from their data that some of their patients were sensitive to visible radiations, probably violet and blue, and some to ultraviolet, but one cannot be sure. The case of eczema solare described by Goeckerman, Osterberg and Sheard (1929) seems to have been sensitive to wave lengths in the region of $3000 \AA$, which is the region producing the erythemic response of normal skin.

As stated above, the wave lengths producing hydroa have never been definitely determined. Gottron and Ellinger (1931) have recently reviewed the material on this subject and have added another case. The results are in general somewhat confusing; it would seem that while

\footnotetext{
5 Quartz mercury arc radiation was effective through "nickel oxide glass" (probably the same type as Corning 986) but not through window glass.
}

some patients with hydroa show a greater sensitivity to ultraviolet radiations, others may show an increased tolerance to such radiations. Unfortunately, few of the investigators of this condition have used sunlight in their tests; yet this is the radiation to which the patients are most frequently exposed and it is the most powerful source of visible light readily at hand.

From this brief resumé it would appear that no common etiological factor for photosensitivity in man has been demonstrated, and that there almost certainly exist more than one. Since the etiological factor in photosensitization must be the photoactive compound which absorbs the light, it would seem highly important to attempt to characterize this factor in terms of the wave lengths of light which produce the clinical effects. The determination of this spectral region is as important in the diagnosis and classification of these diseases as is the isolation of the microorganism associated with a bacterial disease.

Since these cases are rare, it is hoped that they will be carefully studied when discovered. The writers would greatly appreciate receiving reports of any such cases and would gladly cooperate in giving advice or assistance where possible.

\section{BIBLIOGRAPHY}

Barber, H. W., Howitt, F. D., and Knott, F. A., Some observations 'on light sensitization. Guy's Hosp. Rep., 1926, 76, 314.

Beinhauer, L. G., Urticaria solaris. Report of a case. Arch. Dermat. and Syph., 1925, 12, 62.

Blum, H. F., Photodynamic action. Physiol. Rev., 1932, $12,23$.

Blum, H. F., Photosensitization. Ann. Int. Med., 1933, $6,877$.

Blum, H. F., and Spealman, C. R., A differentiation between photosensitized and ultra-violet effects on frogs. Am. J. Physiol., 1934, 109, 605.

Cummins, Sunlight urticaria. Arch. Dermat. and Syph. (Proc. New England Derm. Soc.), 1926, 13, 419.

Duke, W. W., Urticaria caused by light. Preliminary report. J. A. M. A., 1923, 80, 1835.

Duke, W. W., Allergy, Asthma, Hay Fever, Urticaria, and Allied Manifestations of Reaction. C. V. Mosby Co., St. Louis, 1925.

Frei, W., Lokale urtikarielle Hautreaktion auf Sonnenlicht. Arch. f. Dermat. u. Syph., 1925, 149, 124.

Goeckerman, W. H., Osterberg, A. E., and Sheard, C., Eczema solare in a case of hematoporphyrinuria. Arch. Dermat. and Syph., 1929, 20, 501.

Gottron, H., and Ellinger, F., Beitrag zur Klinik der Porphyrie. Arch. f. Dermat. u. Syph., 1931, 164, 11. 
Hausmann, W., and Krumpel, O., Uber die Absorption der Porphyrine im Ultraviolett. Biochem. Ztschr., 1927, 186, 203.

Krogh, A., The Anatomy and Physiology of the Capillaries. Yale University Press, New Haven, 1929, 3d ed.

Laurens, H., Physiological Effects of Radiant Energy. New York, Chemical Catalogue Co., 1933.

Lewis, T., The Blood Vessels of the Human Skin and Their Responses. Shaw and Sons, London, 1927.

Luckiesh, M., Holladay, L. L., and Taylor, A. H., Reaction of untanned human skin to ultraviolet radiation. J. Optic. Soc. America, 1930, 20, 423.

Rasch, C., Some historical and clinical remarks on the effect of light on the skin and skin diseases. Proc. Roy. Soc. Med., Section on Dermatology, 1926, 20, 11.

Templeton, H. J., and Lunsford, C. J., Eczema solare and porphyria. Arch. Dermat. and Syph., 1932, 25, 691.

Treibs, A., Uber die Ultraviolett Absorption der Porphyrine. Ztschr. f. physiol. Chem., 1932, 212, 33.
Vallery-Radot, Pasteur, Blamoutier, P., Besancon, J., and Saidman, J., Urticaire solaire. Bull. et mém. Soc. méd. d. hôp. de Paris, 1926, 50, 1116.

Vallery-Radot, Pasteur, Blamoutier, P., Stehelin, J., and Saidman, J., Urticaire solaire. (Présentation de la malade.) Bull. et mém. Soc. méd. d. hôp. de Paris, 1928, 52, 1122.

Weiss, E., Urticaria solaris. J. Allergy, 1932, 3, 192.

Warburg, O., and Christian, W., Uber das gelbe Ferment und seine Wirkungen. Biochem. Ztschr., 1933, 266, 377.

Ward, S. B., Erythema and urticaria with a condition resembling angeioneurotic edema, caused only by exposure to the sun's rays. New York State J. Med., 1905, 81, 742.

Wucherpfennig, V., Pathologische Lichtüberempfindlichkeit in qualitativer und quantitativer Hinsicht, nebst Untersuchungen zur Pathogenese der Lichtquaddel. Arch. f. Dermat. u. Syph., 1928, 156, 520. 